\title{
Early experience in a breast and ovarian cancer risk management clinic in Malaysia
}

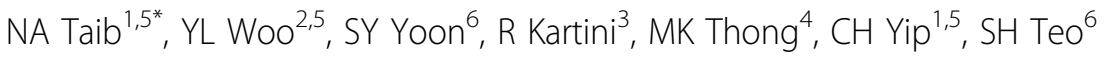 \\ From Familial Aspects of Cancer 2011 Research and Practice: A combined meeting of kConFab, Australian \\ Breast Cancer Family Study, Australian Colorectal Cancer Family Study, Australian Ovarian Cancer Study, \\ Family Cancer Clinics of Australia and New Zealand and kConFab \\ Kingscliff, Australia. 23-26 August 2011
}

\section{Background}

The discovery of BRCA1 and BRCA2 in the mid 1990's has transformed the management of breast and ovarian cancer families. As part of the Malaysian Breast Cancer Genetic Study [MyBrCa], University of Malaya and CARIF have established a genetic counseling, genetic testing and risk management clinic for high-risk breast and ovarian cancer families. We studied the uptake and acceptance of screening and prophylactic surgery amongst women who carry a BRCA1 or BRCA2 mutation.

\section{Methods}

Between Jan 03 and Dec 10, a total of 384 patients in the MyBrCa Study had full sequencing and large rearrangement analysis of both $B R C A 1$ and $B R C A 2$ genes. Of these, 56 index patients (15\%) were found to carry deleterious mutations. All patients and their relatives who carry mutations in these genes were offered followup in a dedicated risk management clinic. The clinic is run jointly by a consultant breast surgeon, gynae-oncologist, a genetic counselor and supported by a consultant radiologist.

\section{Results}

Of 56 index patients, 40 (71\%) chose to know their genetic test results. In addition, 18 female relatives were identified as carriers. Six had passed away. Thus, 52 female carriers are being followed-up [ 43 affected, 9 unaffected individuals]. Of these, 25 women or $62.5 \%$ [24 previously affected by breast cancer and 1 unaffected BRCA carriers] chose to attend a dedicated risk management clinic at University Malaya Medical Centre. Of these 24 affected women, 4 (17\%) already had bilateral mastectomies for bilateral breast cancers, 5 (24\%) chose to have risk reducing mastectomy (RRM), the remaining $16(76 \%)$ chose breast surveillance [only 6 had MRI] and none took up chemoprevention with Tamoxifen. Of the 19 women who did not have previous TAHBSOs, 12 (63\%) chose risk reducing salpingooopherectomy (RRSO).

\section{Conclusions}

The uptake of RRM was lower than RRSO. This study shows that although specialized risk management clinics are acceptable in a high proportion of clients, reasons for not wanting to attend a risk management clinic should be explored.

\begin{abstract}
Author details
${ }^{1}$ Department of Surgery, University Malaya Medical Centre, Malaysia. ${ }^{2}$ Department of Obstetrics and Gynaecology, University Malaya Medical Centre, Malaysia. ${ }^{3}$ Department of Biomedical Imaging, University Malaya Medical Centre, Malaysia. ${ }^{4}$ Department of Paediatrics, University Malaya Medical Centre, Malaysia. ${ }^{5}$ UM Cancer Research Institute, Malaysia. ${ }^{6}$ Cancer Research Initiatives Foundation, Malaysia.
\end{abstract}

Published: 12 April 2012

doi:10.1186/1897-4287-10-S2-A58

Cite this article as: Taib et al:: Early experience in a breast and ovarian cancer risk management clinic in Malaysia. Hereditary Cancer in Clinical Practice 2012 10(Suppl 2):A58. 